\title{
Photovoltaic Detection of Hydrogen Peroxide Employing Potassium Ferricyanide as a Catalyst in the Chemiluminescence of Luminol
}

\author{
Jaechang Yang, Semyung Wang and Jong-Hyun Lee ${ }^{1, *}$ \\ School of Mechatronics, GIST, Gwangju 500-712, Korea \\ ${ }^{1}$ Department of Medical System Engineering and School of Mechatronics GIST, \\ Gwangju 500-712, Korea
}

(Received October 23, 2013; accepted May 13, 2014)

Key words: hydrogen peroxide, photovoltaic detection, luminol, chemiluminescence, potassium ferricyanide

A photovoltaic measurement system is fabricated to detect hydrogen peroxide $\left(\mathrm{H}_{2} \mathrm{O}_{2}\right)$ in a solution based on the chemiluminescence of luminol with potassium ferricyanide and potassium hydroxide as catalysts. A silicon-based positive/intrinsic/negative (PIN) photodiode is employed to quantitatively measure the chemiluminescent light generated from luminol (5-amino-2, 3-dihydro-1, 4-phthalazinedione). Instead of the mixture of luminol and catalysts (MLC) contained in water, the MLC is prepared in powder form enabling $\mathrm{H}_{2} \mathrm{O}_{2}$ detectability at high concentration intended for agricultural applications. Unlike horseradish peroxidase (HRP), potassium ferricyanide (non-biomaterial) can be stored for a longer period at room temperature without being denatured and without any sophisticated equipment for cooling. For various $\mathrm{H}_{2} \mathrm{O}_{2}$ concentrations, the peak value, integration value and maximum slope of the output voltage are measured and are discussed in terms of complexity, linearity and measurement speed.

\section{Introduction}

The advent of microelectrodes has opened new areas of study and has significantly improved the quality of electroanalytical data. ${ }^{(1,2)}$ In particular, electrical sensors that can detect hydrogen peroxide $\left(\mathrm{H}_{2} \mathrm{O}_{2}\right)$ are promising in many fields of application, for instance, pharmaceutical, clinical, environmental, mining, textile, and food manufacturing industries. ${ }^{(3)}$

The development of detection systems that can determine the precise $\mathrm{H}_{2} \mathrm{O}_{2}$ concentration can be beneficial for applications in agriculture in a concentration range of $0.003-0.3 \% . \mathrm{H}_{2} \mathrm{O}_{2}$ can be used instead of pesticides to prevent diseases and eliminate

${ }^{*}$ Corresponding author: e-mail: jonghyun@gist.ac.kr 
insects in the cultivation of crops. ${ }^{(4-6)} \mathrm{H}_{2} \mathrm{O}_{2}$ is currently registered as a biochemical pesticide in the US, and has a variety of agricultural uses for preventing the proliferation of microbes that cause plant diseases. ${ }^{(7)}$ There was a study in which melon plants were treated with approximately $0.07 \% \mathrm{H}_{2} \mathrm{O}_{2}$ to enrich the sugar content in the melon. ${ }^{(8)}$

In addition, there was a report describing $\mathrm{H}_{2} \mathrm{O}_{2}$ being employed as a tool for controlling sea lice on Atlantic salmon in the UK.(9) According to this research, about $0.05 \%$ $\mathrm{H}_{2} \mathrm{O}_{2}$ was adequate at a temperature range between 8 and $13.5^{\circ} \mathrm{C}$ to eradicate sea lice without damaging the salmon. $\mathrm{H}_{2} \mathrm{O}_{2}$ can also be used for detaching the parasite flagellate Cryptobia sp. from the gills of the juvenile marbled rockfish Sebastiscus marmoratus. ${ }^{(10)}$

Various methods of detecting $\mathrm{H}_{2} \mathrm{O}_{2}$ have been reported. ${ }^{(11-15)}$ There were advances in the detection of $\mathrm{H}_{2} \mathrm{O}_{2}$ in the low concentration below $0.003 \%$. It is, however, difficult to find research on $\mathrm{H}_{2} \mathrm{O}_{2}$ measurement at the high concentration (between 0.003 and $0.3 \%$ ) that has been frequently utilized in agricultural applications. Meanwhile, the photovoltaic detection system can provide an alternative solution to the above-mentioned detection methods of high-concentration $\mathrm{H}_{2} \mathrm{O}_{2}$. The research groups of Aizawa et al. ${ }^{(16)}$ and Kim et al. ${ }^{(17)}$ suggested a photovoltaic method for determining the $\mathrm{H}_{2} \mathrm{O}_{2}$ concentration using chemiluminescence assays. The basic concept of the chemiluminescent assays is the use of catalysts that cause luminol molecules to be converted to aminophthalate molecules, which results in light emission in the presence of $\mathrm{H}_{2} \mathrm{O}_{2}$ molecules. The chemical reaction is described as follows:

$$
\text { Luminol }+\mathrm{H}_{2} \mathrm{O}_{2} \stackrel{\text { catalyst }}{\longrightarrow} \text { Aminophthalate }+\mathrm{N}_{2}+\mathrm{H}_{2} \mathrm{O}+h v,
$$

where horseradish peroxidase (HRP) is utilized as a catalyst in both previous studies. ${ }^{(16,17)}$ The emitted light in the luminescent reaction has a wavelength of $450 \mathrm{~nm}$.

The photovoltaic detection system for $\mathrm{H}_{2} \mathrm{O}_{2}$ has the advantages of better portability, low cost, and low power dissipation over other detection methods that additionally require optical peripheral devices for measurement. ${ }^{(18)}$ Furthermore, since only the mixture of luminol and catalyst needs to be replaced, the detection system can be used repeatedly. The emitted light enters the photodiode without altering the characteristics of the photodiode, and this is a significant difference from methods using coated films which are chemically converted after the reaction. Good repeatability is expected in the detection system since the photodiode was reused with the same amount of a mixture of luminol and catalysts (MLC) for every measurement, confirming its high repeatability.

In our study, potassium ferricyanide is used as a catalyst instead of HRP. Utilizing potassium ferricyanide has several advantages over HRP. Potassium ferricyanide can be stored for a much longer time than HRP at room temperature without the need for cooling. This is because potassium ferricyanide is not a biomaterial so it is not denatured even under relatively harsh conditions. The price of potassium ferricyanide is another advantage over HRP. To enable the measurement at high concentrations, a mixture containing luminol, potassium ferricyanide and potassium hydroxide was prepared in powder form rather than dissolving them in water. This is to make the concentrations of luminol and catalysts high, which enables the measurement of $\mathrm{H}_{2} \mathrm{O}_{2}$ at high concentration. 


\section{Materials and Methods}

\subsection{Design}

Figure 1 indicates the schematic design of the proposed photovoltaic $\mathrm{H}_{2} \mathrm{O}_{2}$ detection system. The MLC (potassium ferricyanide and potassium hydroxide) is contained inside a hole that is located at the center of a PVC chamber. PVC was selected as the material for the chamber because it is not transparent, so it can block the effect of ambient light on the photodiode.

To measure the $\mathrm{H}_{2} \mathrm{O}_{2}$ concentration, the water containing $\mathrm{H}_{2} \mathrm{O}_{2}$ was injected using a syringe. An opaque plate was attached to the outer surface of the needle of the syringe to block the ambient light, which operates as a noise for the output signal. The effect of temperature change on performance might also be negligible in our experiments because all of the samples (luminol, potassium ferricyanide, potassium hydroxide and hydrogen peroxide) were stored at room temperature $\left(25^{\circ} \mathrm{C}\right)$ during all the experiments.

The injected $\mathrm{H}_{2} \mathrm{O}_{2}$ generates an oxidant resulting from the work of the catalysts (potassium hydroxide and potassium ferricyanide). The generated oxidant and luminol undergo a chemiluminescence reaction in which light with a wavelength of $450 \mathrm{~nm}$ is generated. The generated light is detected by the photodiode, which is located right below the hole of the chamber. A photodiode is attached to the bottom of the PVC chamber by inserting double-sided tape, which prevents leakage of chemical waste after the chemical reaction.

The chemical reaction of the chemiluminescence of luminol involving the catalysts (potassium hydroxide and potassium ferricyanide) in the presence of $\mathrm{H}_{2} \mathrm{O}_{2}$ is described as follows.

$$
\begin{aligned}
& 2 \mathrm{~K}_{3}\left[\mathrm{Fe}(\mathrm{CN})_{6}\right]+2 \mathrm{KOH}+\mathrm{H}_{2} \mathrm{O}_{2} \rightarrow 2 \mathrm{~K}_{4}\left[\mathrm{Fe}(\mathrm{CN})_{6}\right]+2 \mathrm{H}_{2} \mathrm{O}+\mathrm{O}_{2} \\
& \mathrm{C}_{8} \mathrm{H}_{7} \mathrm{~N}_{3} \mathrm{O}_{2} \text { (Luminol) }+\mathrm{O}_{2} \rightarrow \text { Aminophthalate }+\mathrm{N}_{2}+\mathrm{H}_{2} \mathrm{O}+\mathrm{hv}
\end{aligned}
$$

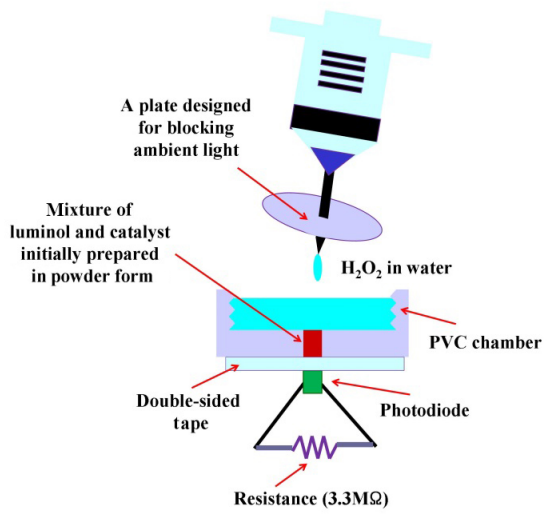

Fig. 1. (Color online) Schematic of proposed photovoltaic $\mathrm{H}_{2} \mathrm{O}_{2}$ detection system. 
The resulting light emitted with a wavelength of $450 \mathrm{~nm}$ arrives at the photodiode, which is placed below the chamber containing the MLC. After the arrival of light, electrical carriers are generated inside the photodiode, and the resulting electrical signal is measured as a form of voltage signal at a $3.3 \mathrm{M} \Omega$ resistor connected to the photodiode.

\subsection{Preparation of chemicals and photodiode}

Potassium ferricyanide and potassium hydroxide were obtained from OCI Company Ltd. (Seoul, Korea). Luminol was from Dae Jung Chemicals \& Metals Company Ltd. (Siheung City, Gyeongido, Korea). Hydrogen peroxide was purchased from Duksan Pure Chemicals (Ansan City, Gyeongido, Korea).

A silicon positive/intrinsic/negative (PIN) photodiode (Osram Opto Semiconductors Co., SFH $206 \mathrm{~K}$, Germany) was purchased for the proposed application. It is suitable for applications in the wavelength region between 400 and $1100 \mathrm{~nm}$. According to the information provided by Osram Opto Semiconductors Co., the employed diode has a relative spectral sensitivity of about $20 \%$ at a wavelength of around $450 \mathrm{~nm}$ to the highest sensitivity at $850 \mathrm{~nm}$. The light sensitive area was $7.02 \mathrm{~mm}^{2}$.

According to reactions (2) and (3), the molar ratio of luminol, potassium ferricyanide and potassium hydroxide is $1: 2: 2$ and the corresponding weight ratio is 1:3.72:0.633. The actual weight ratio of the MLC used in the experiment was 1:2:2. Luminol, which is an essential material for light emission in the reaction, was actually provided in greater abundance relative to potassium ferricyanide. Moisture-absorbing potassium hydroxide was also used in greater abundance to prepare a mixture with better uniformity.

The prepared MLC (mixture of luminol, potassium ferricyanide and potassium hydroxide) was placed inside the hole that was placed on the front side of the photodiode. The volume of the hole of the chamber was $40 \mu \mathrm{l}$. A resistor with $3.3 \mathrm{M} \Omega$ was connected to the photodiode to measure the voltage signal by utilizing an oscilloscope as described in Fig. 1.

\section{Experimental Results}

The research groups of Aizawa et al.(16) and Kim et al. ${ }^{(17)}$ measured $\mathrm{H}_{2} \mathrm{O}_{2}$ concentration below $0.034 \%$ for biosensor applications. In our research, measurement was performed up to $0.25 \%$ for applications in agriculture rather than biosensors. To enable the measurement at high $\mathrm{H}_{2} \mathrm{O}_{2}$ concentrations, we prepared luminol and a catalyst in powder form rather than dissolving them in water. Thus, the MLC initially exists in powder form under dry condition. This is intended to obtain a larger output signal with a higher speed because a relatively larger amount of luminol and catalysts can be consumed after the injection of $\mathrm{H}_{2} \mathrm{O}_{2}$ into the chamber compared with the case when the MLC is prepared in a liquid solution. As no water is added to the MLC before the injection of the solution containing $\mathrm{H}_{2} \mathrm{O}_{2}$, luminol with an extremely high concentration can be consumed in the reaction with $\mathrm{H}_{2} \mathrm{O}_{2}$ after injection. In our experiments, $40 \mu \mathrm{l}$ of powder of the MLC is placed inside the hole of the chamber, followed by the injection of $0.5 \mathrm{ml}$ of water containing $\mathrm{H}_{2} \mathrm{O}_{2}$. 
Figure 2 shows a picture of the proposed photovoltaic detection system for $\mathrm{H}_{2} \mathrm{O}_{2}$ detection. As shown in the top image, a photodiode is attached to the PVC chamber by inserting double-sided tape. Moreover, as shown in the bottom image, the resistor and the oscilloscope (Agilent Technologies, DSO6012A) are connected in parallel to the photodiode for measurement of the voltage as an output signal.

Figure 3 shows the output voltage of the photodiode in the time domain for various $\mathrm{H}_{2} \mathrm{O}_{2}$ concentrations from 0.0039 to $0.25 \%$ because this region is adequate for agricultural applications. The real-time measurements were performed repeatedly using one photodiode for each concentration to take advantage of the reusability of the photodiode. The time for the chemiluminescence emission to reach the maximum is less than $5 \mathrm{~s}$ after the injection of $\mathrm{H}_{2} \mathrm{O}_{2}$ into the MLC. Moreover, the chemiluminescence emission decays completely in less than $5 \mathrm{~s}$ from the time the signal reaches the maximum value.

As shown in Fig. 4, the output peak voltage of the photodiode increases with an increase in the $\mathrm{H}_{2} \mathrm{O}_{2}$ concentration in the region below $0.25 \%$. In the relatively higher concentration region, saturation of the output voltage can be observed. This phenomenon can be explained by two reasons. The first reason can be attributed to the higher generation speed of by-products in the higher $\mathrm{H}_{2} \mathrm{O}_{2}$ concentration region that hinders further chemiluminescent reaction by blocking $\mathrm{H}_{2} \mathrm{O}_{2}$ molecules from arriving at the position of luminol and the catalysts. Besides the blocking of by-products, the saturation can be explained by the relationship between the generated photon energy in the chemiluminescence and the output energy at the resistor as described in eq. (4). The generated photon energy is equal to the electrical energy at the resistor.

$$
k \cdot\left(h v \cdot V \cdot C_{\mathrm{H} 2 \mathrm{O} 2}\right)=\int\left(V_{\text {out }}^{2} / R\right) \mathrm{d} t
$$

$k$ : constant regarding the distribution of luminol and catalysts

$h$ : Planck constant

$v$ : frequency of generated light

$V$ : volume of hole in PVC chamber

$C_{\mathrm{H}_{2} 2}: \mathrm{H}_{2} \mathrm{O}_{2}$ concentration in injected liquid

$V_{\text {out }}$ : output voltage

$R$ : resistance of resistor

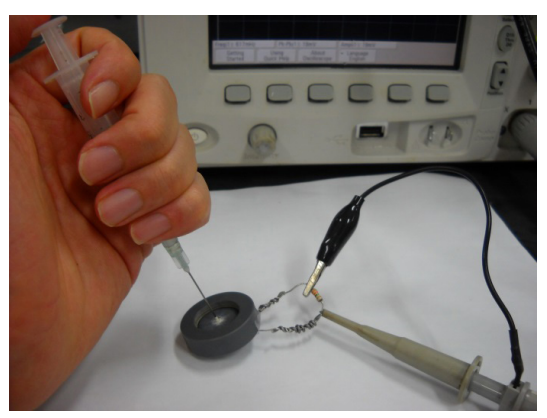

Fig. 2. (Color online) Picture of the proposed photovoltaic $\mathrm{H}_{2} \mathrm{O}_{2}$ detection system connected to the oscilloscope for the measurement. 

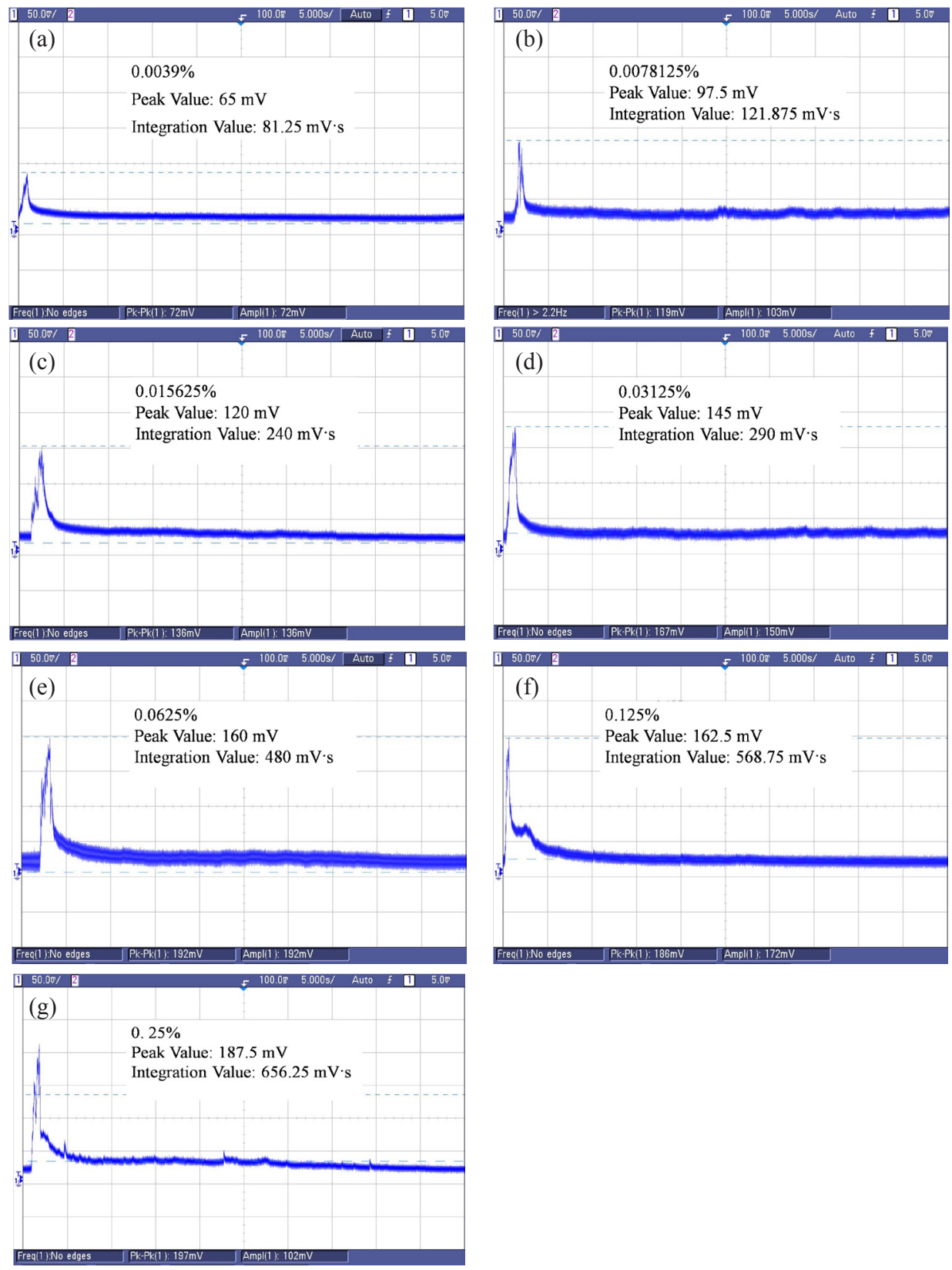

Fig. 3. (Color online) Output voltage vs time for various $\mathrm{H}_{2} \mathrm{O}_{2}$ concentrations using the MLC in powder form. Scale of time domain: 5 s/division. (a) Output voltage vs time for $0.0039 \%$ $\mathrm{H}_{2} \mathrm{O}_{2}$ concentration, (b) output voltage vs time for $0.0078125 \% \mathrm{H}_{2} \mathrm{O}_{2}$ concentration, (c) output voltage vs time for $0.015625 \% \mathrm{H}_{2} \mathrm{O}_{2}$ concentration, (d) output voltage vs time for $0.03125 \% \mathrm{H}_{2} \mathrm{O}_{2}$ concentration, (e) output voltage vs time for $0.0625 \% \mathrm{H}_{2} \mathrm{O}_{2}$ concentration, (f) output voltage vs time for $0.125 \% \mathrm{H}_{2} \mathrm{O}_{2}$ concentration, and (g) output voltage vs time for $0.25 \% \mathrm{H}_{2} \mathrm{O}_{2}$ concentration. 


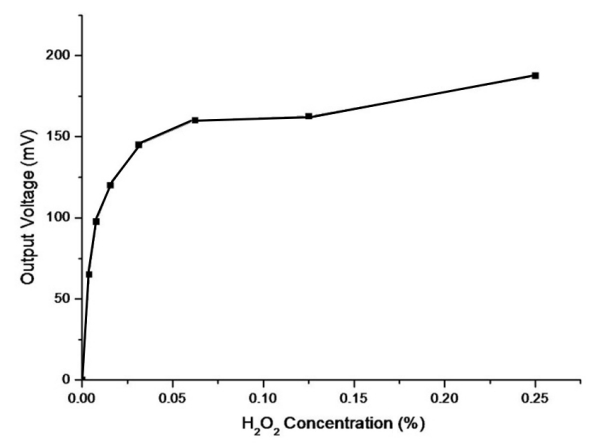

Fig. 4. Output peak voltage vs $\mathrm{H}_{2} \mathrm{O}_{2}$ concentration in the measurement using the MLC in powder form. (Conversion ratio: $1 \% \mathrm{H}_{2} \mathrm{O}_{2}=294.1 \mathrm{mM} \mathrm{H}_{2} \mathrm{O}_{2}$ )

If $V_{\text {out }}$ is treated as a constant (although it is not the exact case) and the time domain is assumed to be always the same in the integral operation, $V_{\text {out }}$ is proportional to $\left(C_{\mathrm{H} 202}\right)^{1 / 2}$. This proportional relation between $V_{\text {out }}$ and $\left(C_{\mathrm{H} 2 \mathrm{O} 2}\right)^{1 / 2}$ may explain the saturation of the peak output voltage in the relatively higher concentration region.

Because of the fluctuation of the output peak voltage, it is quite difficult to obtain good repeatability and linearity in the measurement. Therefore, a more stable characteristic parameter was employed. To confirm the possibility of obtaining a stable output signal, the output voltage is integrated over the time domain, as shown in Fig. 5. The integrated values of voltage have better linearity with an increase in the $\mathrm{H}_{2} \mathrm{O}_{2}$ concentration in the measurement range.

The second experiment using the photodiode was conducted to gain a new characteristic parameter of the $\mathrm{H}_{2} \mathrm{O}_{2}$ detection system, the maximum slope of output voltage in the time domain. To accurately measure the slope, another experiment was performed under the same conditions as in the previous measurement shown in Fig. 3 ( 5 s per division in the oscilloscope), except with a tenfold magnitude in the time domain $(0.5 \mathrm{~s}$ per division). It is noticeable that the maximum slope is generated before the output peak voltage allowing fast measurement. The tendency of the obtained peak value was similar to the result shown in Fig. 4. The variation of the peak value between the experiments was as small as $10 \%$, which implies that the measured output voltage revealed a good repeatability. As shown in the slope measurement in Fig. 6 , the maximum slope of the output voltage increased with an increase in the $\mathrm{H}_{2} \mathrm{O}_{2}$ concentration in the measurement range.

To clarify the reason why the log value of the maximum slope was proportional to the $\log$ value of $\mathrm{H}_{2} \mathrm{O}_{2}$ concentration, the chemical reaction rate as a function of the concentration of the chemical material is described in eq. (5). It is known that for a chemical reaction $m \mathrm{~A}+n \mathrm{~B} \rightarrow p \mathrm{C}+q \mathrm{D}$, the reaction rate is defined as follows.

$$
r=k(T)[\mathrm{A}]^{m}[\mathrm{~B}]^{n}
$$

$r$ : reaction rate

$k(T)$ : reaction rate coefficient

[A], [B]: concentrations of A and B

$m, n$ : reaction order 

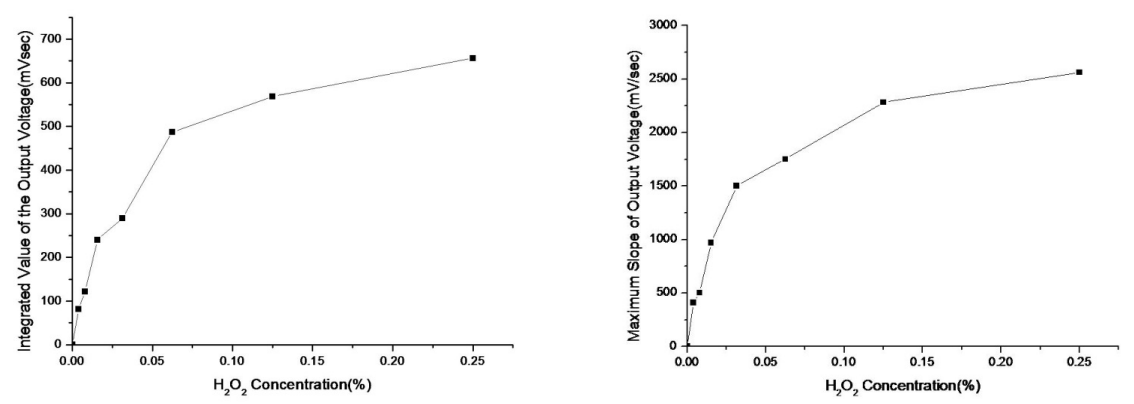

Fig. 5 (left). Output voltage value integrated over time domain vs $\mathrm{H}_{2} \mathrm{O}_{2}$ concentration in the measurement using the MLC in powder form. (Conversion ratio: $1 \% \mathrm{H}_{2} \mathrm{O}_{2}=294.1 \mathrm{mM} \mathrm{H}_{2} \mathrm{O}_{2}$ )

Fig. 6 (right). Maximum slope of output voltage vs $\mathrm{H}_{2} \mathrm{O}_{2}$ concentration in the measurement using the MLC in powder form. (Conversion ratio: $1 \% \mathrm{H}_{2} \mathrm{O}_{2}=294.1 \mathrm{mM} \mathrm{H}_{2} \mathrm{O}_{2}$ )

From eq. (5), $\log (r)$ is proportional to $\log [\mathrm{A}]$ and $\log [\mathrm{B}]$. In our application, the only variable was the $\mathrm{H}_{2} \mathrm{O}_{2}$ concentration, whereas the quantities of luminol and catalysts inside the chamber were constant. Therefore, the $\log$ value of the reaction rate is proportional to the log value of the $\mathrm{H}_{2} \mathrm{O}_{2}$ concentration.

Figure 7 describes the correlation between log (slope of output voltage) and $\log \left[\mathrm{H}_{2} \mathrm{O}_{2}\right]$. Better linearity can be obtained by the method using the maximum slope compared with the method using the peak value. However, even if better linearity can be obtained, the method utilizing the maximum slope has a shortcoming, that is, it additionally requires taking the derivative of the output voltage in the time domain.

Three types of $\mathrm{H}_{2} \mathrm{O}_{2}$ detection method were proposed in this paper: peak voltage, voltage area and maximum voltage slope. The measurement of the peak output voltage is the simplest method. However, measurements of the output voltage area and output voltage slope enable better linearity of the output signal. The measurement of the output voltage area produces better reliability, but a longer measurement time is required. The measurement of the output voltage slope is the fastest measurement while additional electrical devices for the differential operations are needed for practical applications. As a future plan, the peak output, voltage area and maximum voltage slope can be improved by optimizing the MLC component ratio, and by using a reflector to redirect divergent light emissions back to the photodiode.

\section{Conclusions}

A photovoltaic detection system was designed for measuring hydrogen peroxide for agricultural applications. The photovoltaic detection system has the advantages of better portability, lower power dissipation and lower manufacturing cost. Potassium ferricyanide was employed as a catalyst because it can be stored at room temperature 


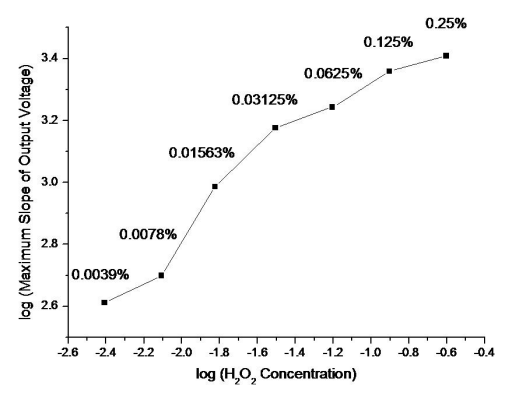

Fig. 7. $\log$ (maximum slope of output voltage) vs $\log \left(\mathrm{H}_{2} \mathrm{O}_{2}\right.$ concentration). (Conversion ratio: $1 \% \mathrm{H}_{2} \mathrm{O}_{2}=294.1 \mathrm{mM} \mathrm{H}_{2} \mathrm{O}_{2}$ )

for a longer period than HRP. To enhance the sensitivity, MLC was prepared at a high concentration in powder form instead of solution form. Furthermore, since only the MLC needs to be replaced, the detection system can be used repeatedly, which is a significant difference from other methods using chemically converted films.

The peak value of the output voltage of the photodiode increased with an increase in the $\mathrm{H}_{2} \mathrm{O}_{2}$ concentration as predicted. The linearity of the output voltage was enhanced when the integration value over the time domain was utilized instead of the peak value. Using the maximum slope of the output voltage also enhanced the linearity and enabled the fastest measurement compared with the two other methods. Based on this research, the proposed photovoltaic $\mathrm{H}_{2} \mathrm{O}_{2}$ detection system has a potential for contributing to the precise measurement of $\mathrm{H}_{2} \mathrm{O}_{2}$ concentration with a simpler measurement set up and with a lower cost than the conventional $\mathrm{H}_{2} \mathrm{O}_{2}$ detection methods.

\section{Acknowledgements}

This research was supported by a grant from the Institute of Medical System Engineering (iMSE) in GIST, Korea.

\section{References}

1 H. Hosono, W. Satoh, J. Fukuda and H. Suzuki: Sens. Mater. 19 (2007) 191.

2 J. Yang, H. Jung, G. J. Lee, J. Y. Kang, J. G. Koo, J. M. Park, K. S. Park and S.H. Kong: Jpn. J. Appl. Phys. 47 (2008) 6943.

3 P. Rameshkumar and R. Ramaraj: Journal of Applied Electrochemistry 43 (2013) 1005.

4 I. Vänninen and H. Koskula: Crop Protection 17 (1998) 547.

5 H. Byun and S. Choi: Journal of the Korean Society for Horticultural Science 44 (2003) 859 (in Korean).

6 I. Cho, W. Lee, K. Kwan, Y. Woo and K. Lee: Journal of Bio-Environment Control 18 (2009) 297.

7 D. L. Sudakin: Toxicol Rev 22 (2003) 83.

8 K. Ozaki, A. Uchida, T. Takabe, F. Shinagawa, Y. Tanaka, T. Takabe, T. Hayashi, T. Hattori, A. K. Rai and T. Takabe: Journal of Plant Physiology 166 (2009) 569. 
9 D.W. Bruno and R.S. Reynard: Aquaculture International 2 (1994) 10.

10 K. Tensha and K. Momoyama: Bull. Yamaguchi Pref. Fish. Res. Ctr. 4 (2006) 167 (in Japanese).

11 F. Luo, J. Yin, F. Gao and L. Wang: Microchim Acta 165 (2009) 23.

12 Q. Wang, Y. Yun and J. Zheng: Microchim Acta 167 (2009) 153.

13 Z. Yan, J. Zhao, L. Qin, F. Mu, P. Wang and X. Feng: Microchim Acta 180 (2013) 145.

14 K. Zhang, L. Zhang, J. Xu, C. Wang, T. Geng, H. Wang and J. Zhu: Microchim Acta 171 (2010) 139.

15 Y. Zhang, H. Q. Luo and N. B. Li: Bioprocess Biosyst Eng 34 (2011) 215.

16 M. Aizawa, Y. Ikariyama and H. Kuno: Analytical Letters 17 (1984) 555.

17 H. Kim, C. Kang, M. Kang, J. Park and N. Min: Journal of the Korean Physical Society 42 (2003) 336.

18 J. Zheng, Y. Yan, X. Wang, W. Shi, H. Ma, Y. Zhao and J. Yao: Advanced Optical Materials 24 (2012) 194. 